\title{
UV-photoprocessing of interstellar ice analogs: New infrared spectroscopic results
}

\author{
G. M. Muñoz Caro ${ }^{1,2}$ and W. A. Schutte ${ }^{1}$ \\ 1 Raymond and Beverly Sackler Laboratory for Astrophysics, Leiden Observatory, 2300 RA Leiden, The Netherlands \\ 2 Institut d'Astrophysique Spatiale, UMR 8617, Bât. 121, Campus Paris XI, 91405 Orsay, France
}

Received 14 November 2002 / Accepted 20 August 2003

\begin{abstract}
We simulate experimentally the physical conditions present in dense clouds by means of a high vacuum experimental setup at low temperature $T \approx 12 \mathrm{~K}$. The accretion and photoprocessing of ices on grain surfaces is simulated in the following way: an ice layer with composition analogous to that of interstellar ices is deposited on a substrate window, while being irradiated by ultraviolet (UV) photons. Subsequently the sample is slowly warmed up to room temperature; a residue remains containing the most refractory products of photo- and thermal processing. In this paper we report on the Fourier transform-infrared (FT-IR) spectroscopy of the refractory organic material formed under a wide variety of initial conditions (ice composition, UV spectrum, UV dose and sample temperature). The refractory products obtained in these experiments are identified and the corresponding efficiencies of formation are given. The first evidence for carboxylic acid salts as part of the refractory products is shown. The features in the IR spectrum of the refractory material are attributed to hexamethylenetetramine $\left(\mathrm{HMT},\left[\left(\mathrm{CH}_{2}\right)_{6} \mathrm{~N}_{4}\right]\right)$, ammonium salts of carboxylic acids $\left[\left(\mathrm{R}-\mathrm{COO}^{-}\right)\left(\mathrm{NH}_{4}^{+}\right)\right]$, amides $\left[\mathrm{H}_{2} \mathrm{NC}(=\mathrm{O})-\mathrm{R}\right]$, esters $\left[\mathrm{R}-\mathrm{C}(=\mathrm{O})-\mathrm{O}-\mathrm{R}^{\prime}\right]$ and species related to polyoxymethylene (POM, $\left.\left[\left(-\mathrm{CH}_{2} \mathrm{O}-\right)_{n}\right]\right)$. Furthermore, evidence is presented for the formation of $\mathrm{HMT}$ at room temperature, and the important role of $\mathrm{H}_{2} \mathrm{O}$ ice as a catalyst for the formation of complex organic molecules. These species might also be present in the interstellar medium (ISM) and form part of comets. Ongoing and future cometary missions, such as Stardust and Rosetta, will allow a comparison with the laboratory results, providing new insight into the physico-chemical conditions present during the formation of our solar system.
\end{abstract}

Key words. infrared: ISM - ISM: lines and bands - methods: laboratory - ultraviolet: ISM - ISM: dust, extinction

\section{Introduction}

Dense molecular clouds in the ISM, with densities ranging from $10^{3}-10^{6}$ atoms $\mathrm{cm}^{-3}$ and kinetic temperatures in the range $10-50 \mathrm{~K}$, are the birthplaces of stars. Dust particles in dense clouds accrete molecules from the gas phase, getting coated with an ice mantle. The composition of the ice mantle depends on the local environment; it is dominated by $\mathrm{H}_{2} \mathrm{O}$ ice, while $\mathrm{CO}, \mathrm{CO}_{2}, \mathrm{CH}_{3} \mathrm{OH}$, and $\mathrm{NH}_{3}$ are commonly observed (Gibb et al. 2001).

Laboratory experiments simulating the energetic and thermal processing of interstellar (IS) ice analogs show the formation of new molecules, radicals, and other fragments. A small fraction of the new species is of high molecular mass, up to $200 \mathrm{amu}$, being refractory at room temperature. This material is generally called refractory organic residue or simply residue. Large organic compounds are produced either by ice photoprocessing (Agarwal et al. 1985; Briggs et al. 1992; Bernstein et al. 1995, 2002; Muñoz Caro et al. 2002, 2003) or by ion bombardment (e.g. Strazzulla \& Baratta 1992; Kobayashi et al. 1995; Kaiser \& Roessler 1998; Cottin et al. 2001).

Send offprint requests to: G. M. Muñoz Caro, e-mail: Guillermo.Munoz-Caro@ias.u-psud.fr
These results indicate that IS ices could be the birthplaces of complex organic molecules. This possibly has important implications for the composition of the dust in the ISM and in the solar nebula. The delivery of such organic species to the surface of the early Earth by comets may have provided the basic ingredients required for the origin of life (Oró 1961; Greenberg 1986; Bernstein et al. 2002; Muñoz Caro et al. 2002). The composition of cometary organics can be also used as indicators of the physico-chemical conditions in the solar nebula.

This article reports on the experimental simulation of ice photoprocessing in the ISM. The effects of irradiation and thermal processing of the ice were monitored in situ by detailed FT-IR spectroscopy. Since the main components of the residues, i.e., organic acid salts and hexamethylenetetramine, have characteristic infrared features, FT-IR spectroscopy is a sensible tool to get a global overview of the nature of the organic photochemistry. For the first time, detailed quantitative analysis was performed on the effects of essential free parameters, such as ice composition, UV dose, photon energy, and temperature. In particular, irradiation experiments were performed with varying ice composition. In selecting the "standard" ice composition for our experiments, the observational constraints were taken into account. An ice mixture of molar 
composition $\mathrm{H}_{2} \mathrm{O}: \mathrm{CH}_{3} \mathrm{OH}: \mathrm{NH}_{3}: \mathrm{CO}: \mathrm{CO}_{2}=2: 1: 1: 1: 1$ was selected as standard. $\mathrm{A}_{2} \mathrm{O}: \mathrm{CH}_{3} \mathrm{OH}: \mathrm{CO}_{2}=2: 1: 1$ ice resembles the abundances found close to protostellar sources (Gerakines et al. 1999; Ehrenfreund et al. 1999; Dartois et al. 1999; Gibb et al. 2001). It should be noted that the line of sight abundances of $\mathrm{CH}_{3} \mathrm{OH}$ and $\mathrm{CO}_{2}$ is $\sim 5-10$ times lower than the abundances found close to the protostellar sources due to the dominance of $\mathrm{H}_{2} \mathrm{O}$ ice in the cold outer regions (Gerakines et al. 1999). It was recently shown that, contrary to earlier views (Gibb et al. 2001; Gürtler et al. 2002), most of the ammonia in IS ices is probably present in the form of the ammonium ion, $\mathrm{NH}_{4}^{+}$, rather than as $\mathrm{NH}_{3}$ (Taban et al. 2003; Schutte \& Khanna 2003). In this paper, however, $\mathrm{NH}_{3}$ is used as a component of the starting ice mixture. We postpone an investigation of the effects of the conversion to $\mathrm{NH}_{4}^{+}$to future work. Furthermore, the thermal evolution of the chemical processes responsible for the main residue components was monitored. Our work led to the identification of the most prominent feature of the residue, at $1586 \mathrm{~cm}^{-1}$. Evidence is shown for the catalytic properties of $\mathrm{H}_{2} \mathrm{O}$ ice in the formation of organic species.

The layout of this paper is as follows: in Sect. 2 we enumerate the scenarios where ice photoprocessing is expected to play a role. Section 3 describes the experimental protocol and the use of FT-IR spectroscopy. The experimental results are presented in Sect. 4 and discussed in Sect. 5. The astrophysical implications of the results are derived in Sect. 6 .

\section{Photoprocessing of ices in the ISM}

Ice mantles in dense clouds are, to some extent, energetically processed by UV photons and cosmic ray particles. Observational evidence for photoprocessing in dense clouds is derived from the reduction of the $3.4 \mu \mathrm{m}$ feature, which can be explained by exposure of the grains to UV radiation (Muñoz Caro et al. 2001; Mennella et al. 2001).

Photoprocessing may occur due to penetration of UV into dense clouds (Whittet et al. 1998). This effect may be enhanced if the cloud structure is clumpy (Spaans \& van Dishoeck 1997; Beuther et al. 2000). Recent observations show dense clouds are very clumpy. For the molecular cloud Cepheus B, the filling factor, the ratio of average over local densities, is $F_{\mathrm{V}}=2-4 \%$ (Beuther et al. 2000, 2002). Also the presence of neighbouring young massive stars can expose the material within the cloud to intense UV fields, even above the average interstellar field. The typical scale length of the UV penetration in such clouds is $1 \mathrm{pc}$ (Beuther et al. 2000).

Furthermore, photoprocessing may take place in protostellar environments at various stages of the evolution. In particular, UV photons scattered by dust in the bipolar outflow cavities could penetrate the outer regions of the circumstellar environments where ice mantles are present (Spaans et al. 1995). Photolysis will also take place in the outer regions of protoplanetary disks around young stellar objects (YSOs, Aikawa \& Herbst 1999). At the T Tauri phase of the protostellar evolution the intensity of the UV field at $100 \mathrm{AU}$ from the central source, where disk temperatures are $\leq 60 \mathrm{~K}$, can be up to $\approx 10^{12} \mathrm{UV}$ photons $\mathrm{cm}^{-2} \mathrm{~s}^{-1}$ (Herbig \& Goodrich 1986). With such a UV intensity a molecule inside the ice mantle will absorb, for a typical UV cross section of $\sigma_{\mathrm{UV}}=2 \times 10^{-18} \mathrm{~cm}^{2}$, about $1 \mathrm{UV}$ photon per week. As will be reviewed below, such a dose would convert $\sim 10 \%$ of the carbon in the ice to complex organic molecules. Beyond $\approx 100 \mathrm{AU}$, the magnetic field will couple to the gas causing turbulence and vertical mixing of the material in the accretion disk. The mixing time is of the order of $10^{5} \mathrm{yr}$, shorter than the lifetime of the accretion disk, about $(3-10) \times 10^{6} \mathrm{yr}$. This may cause most of the material in the outer disk to be exposed to the stellar photons and to become thoroughly photolyzed (Aikawa et al. 1996, 1999, 2002).

At distances larger than 5-10 AU from a solar-type star, temperatures are low enough to preserve grains coated by ice mantles (Prinn 1993); here dust accretion would lead to comet formation, as it presumably occured in our own solar system. The large abundances of oxygen-rich complex organic molecules found in comet Halley (Kissel \& Krueger 1987; Fomenkova et al. 1994) suggests that energetic processing in the ISM, and/or the solar nebula, cannot be disregarded.

A long standing question is the contribution of UV photons to energetic ice processing in dense clouds as compared to cosmic rays. Detailed calculations of the UV radiation field induced by cosmic rays in dense clouds lead to $\sim 5 \times$ $10^{3} \mathrm{UV}$ photons $\mathrm{cm}^{-2} \mathrm{~s}^{-1}$ for $400 \mathrm{MeV}$ protons. Therefore, in the case of $\mathrm{H}_{2} \mathrm{O}$ ice, the energy deposited in ice mantles by UV photons is $\sim 14$ times larger than for cosmic rays (Shen et al. 2003).

\section{Experimental}

\subsection{Experimental procedure}

The experimental setup is made of stainless steel. It basically consists of a high vacuum chamber where a gas mixture is deposited on a cold finger and irradiated. The system is pumped by a turbo pump (Pfeiffer Balzers TSH $280 \mathrm{H}$ ) backed up by a diaphragm pump (Vacuubran MD4T). The pressure of the system at room temperature is $P \approx 1 \times 10^{-7}$ torr. The low temperatures typical of dense clouds, ranging from 10 to $50 \mathrm{~K}$, are achieved by means of a closed-cycle helium cryostat (Air Products Displex DE-202). At the cold finger the temperature is $T \approx 12 \mathrm{~K}$. For a detailed description of the experimental setup, see Gerakines et al. (1995). The cold finger consists of a sample holder, in which an IR-transparent CsI window is mounted, using indium seals to ensure good thermal conductivity.

The gas mixture is prepared by filling a bulb with different gases while the partial vapor pressures are monitored. The vacuum pressure of the gas line is $P \approx 10^{-5}$ torr. The gas mixtures prepared for our experiments contained, in various proportions: $\mathrm{H}_{2} \mathrm{O}$ (liquid), distilled; $\mathrm{CH}_{3} \mathrm{OH}$ (liquid), Janssen Chimica 99.9\%; $\mathrm{NH}_{3}$ (gas), Praxair 99.999\%; $\mathrm{CO}$ (gas), Praxair 99.997\%; and $\mathrm{CO}_{2}$ (gas), Praxair 99.996\%. $\mathrm{CO}_{2}$ was kept in a separate bulb in order to prevent it from reacting with the ammonia, $\mathrm{NH}_{3}$. Deposition was done through two independent tubes (Gerakines et al. 1995). During the deposition, the ice layer is simultaneously UV-irradiated with a microwave stimulated hydrogen flow discharge lamp (out-

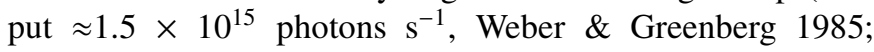




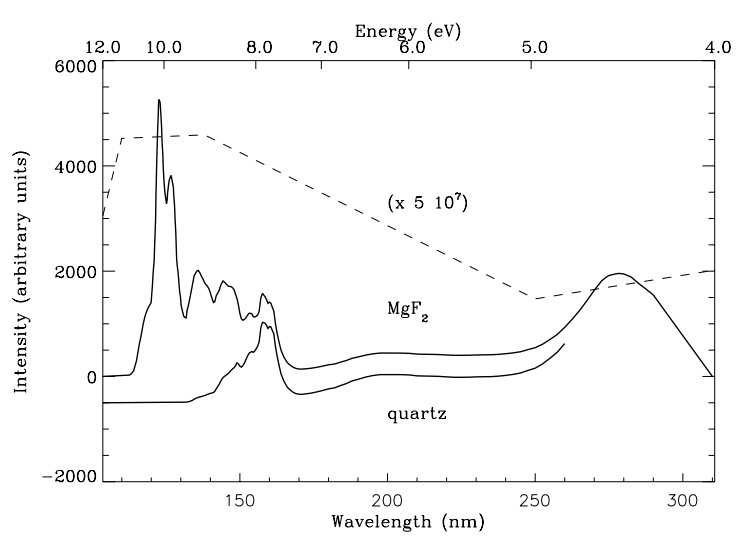

Fig. 1. Emission intensity spectrum, in arbitrary units, of the microwave stimulated hydrogen flow discharge lamp for $\mathrm{agF}_{2}$ window (top, solid line) and a quartz window (bottom, solid line), corresponding to the hard and soft UV spectrum, respectively. Spectra were offset for clarity. For comparison, the radiation field of the diffuse interstellar medium $\left(\times 5 \times 10^{7}\right)$ is included (Jenniskens 1993, and ref. therein).

$E_{\text {photon }}=7.3-10.5 \mathrm{eV}$ ), separated from the vacuum chamber by a $\mathrm{MgF}_{2}$ or a quartz window. The resultant output spectra of the discharge lamp with the two interface windows are shown in Fig. 1. The top solid spectrum corresponds to the $\mathrm{MgF}_{2}$ transmission of the lamp output, with main peak emission at Lyman- $\alpha, 121 \mathrm{~nm}$ line, corresponding to $10.2 \mathrm{eV}$, for a hydrogen pressure $P_{\mathrm{H}}=0.5$ torr (henceforth hard UV spectrum). The bottom solid spectrum corresponds to the quartz transmission with a cutoff at about $140 \mathrm{~nm}$ $(8.9 \mathrm{eV})$ giving an output $\approx 4 \times 10^{14}$ photons $^{-1}$ (henceforth soft UV spectrum). For comparison, the radiation field of the diffuse interstellar medium $\left(\times 5 \times 10^{7}\right)$ is included (Jenniskens 1993, and ref. therein). There is a clear similarity between the radiation field of the diffuse medium and the hard UV spectrum. The extinction encountered upon entering a dense region will have the effect of "softening" the UV field, since more energetic photons face more extinction than less energetic ones (e.g. Kim et al. 1994). To take this effect into account, one irradiation experiment was performed with the soft UV spectrum.

The typical rate of deposition was $2 \times$ $10^{15}$ molecules $\mathrm{cm}^{-2} \mathrm{~s}^{-1}$, and the deposition time was 13 hours, resulting in a final sample thickness of $\sim 30 \mu \mathrm{m}$, assuming a density of $\rho=1 \mathrm{~g} \mathrm{~cm}^{-3}$. The UV photon flux at the position of the sample is $F_{\mathrm{UV}} \approx 5 \times 10^{14}$ photon $\mathrm{cm}^{-2} \mathrm{~s}^{-1}$, resulting in an average dose of $\sim 0.25 \mathrm{UV}$ photon molec $^{-1}$. A long simultaneous deposition and irradiation are required to photolyze ice samples of sufficient size to yield enough residue for subsequent analysis. After irradiation, the system is warmed up gradually by means of a temperature controller (Scientific Instruments Inc. 9600-1) at $1 \mathrm{~K} \mathrm{~min}^{-1}$ until $T=40 \mathrm{~K}$, in order to prevent explosive reactions caused by UV-produced free radicals embedded in the ice (d'Hendecourt et al. 1982). The cryostat is kept on during warm-up to prevent background $\mathrm{H}_{2} \mathrm{O}$ from accreting on the substrate of the deposition. Above $40 \mathrm{~K}$ the warm-up proceeds at about $4 \mathrm{~K} \mathrm{~min}^{-1}$ up to room temperature; at that point the cryostat and temperature controller are turned off, allowing the system to slowly get in thermal equilibrium with the environment.

\subsection{FT-IR analysis}

The evolution of the sample during irradiation and warm-up was monitored by means of infrared transmission spectroscopy (BIO RAD FTS-40A spectrometer) at a resolution of $2 \mathrm{~cm}^{-1}$. For all the experiments, the final residue spectrum was taken after $10 \mathrm{~h}$ at room temperature. At that stage, the sample has stabilized (see Sect. 4.5). All the spectra shown here were scanned while the sample was under high vacuum.

\section{Experimental results}

\subsection{Introduction}

In situ infrared analysis is a suitable technique for quantitative analysis, and the ease of this technique enables a thorough exploration of parameter space. Table 1 summarizes the parameters corresponding to the different experimental runs. Exp. OR1 constitutes the standard experiment which sets the starting-point for the exploration of parameter space. We investigate the effect of the UV dose (Exps. OR1, OR4, and OR5), UV photon energy (Exp. OR7 was performed with the soft UV spectrum, while all other experiments were performed with the hard UV spectrum), starting ice composition (Exp. OR1, OR9-OR13), ice deposition and irradiation at different temperatures (Exps. OR1 and OR6), as well as the concentration of organic ices relative to $\mathrm{H}_{2} \mathrm{O}$ ice (Exps. OR1 and OR16, OR11 and OR14, OR13 and OR15). Exp. OR8, with no irradiation, and Exp. OR10, without carbon components, served as blanks. Exp. OR2 aims to test the reproducibility of the standard, Exp. OR1. The time evolution at room temperature was monitored in Exp. OR3. The values in Table 1 correspond to the final residue spectrum after $10 \mathrm{~h}$ at room temperature (Sect. 3.2).

\subsection{The standard experiment}

For the standard experiment (OR1, Table 1), the $\mathrm{H}_{2} \mathrm{O}: \mathrm{NH}_{3}: \mathrm{CH}_{3} \mathrm{OH}: \mathrm{CO}: \mathrm{CO}_{2}=2: 1: 1: 1: 1$ ice mixture was irradiated at $12 \mathrm{~K}$ with a UV dose of 0.25 photon molec $^{-1}$ and the hard UV spectrum (Fig. 1). Figure 2 shows the resultant spectrum of the residue. Table 2 summarizes the assignments of the various infrared features. The spectrum is dominated by the presence of a very broad feature ranging from 3500 to $2300 \mathrm{~cm}^{-1}$, characteristic of dimers of carboxylic acids, and a number of strong features in the region from 1700 to $1000 \mathrm{~cm}^{-1}$, which also appear in the spectrum of these acids. The strongest peak in this region, at $1586 \mathrm{~cm}^{-1}$, is most probably due to the $-\mathrm{COO}^{-}$antisymmetric stretch of carboxylic acid salts $\left[\left(\mathrm{R}-\mathrm{COO}^{-}\right)\left(\mathrm{NH}_{4}^{+}\right)\right]$. In order to test this assumption, glycolic acid $\left(\mathrm{HOCH}_{2} \mathrm{COOH}\right.$; Aldrich $\left.99 \%\right)$, the most abundant carboxylic acid found in residues (Agarwal et al. 1985; Briggs et al. 1992) and ammonia, $\mathrm{NH}_{3}$, were deposited simultaneously at $12 \mathrm{~K}$. A reaction takes place already at $12 \mathrm{~K}$, leading to the formation of a sharp peak at $1586 \mathrm{~cm}^{-1}$ 
Table 1. Parameters of the experiments. Unless otherwise specified, the experiments were performed with deposition/irradiation at $12 \mathrm{~K}$, and the hard UV spectrum.

\begin{tabular}{|c|c|c|c|c|c|c|c|c|}
\hline $\begin{array}{l}\text { Exp. } \\
\text { OR\# }\end{array}$ & Comment & $\begin{array}{c}\text { Ice mixture } \\
\mathrm{H}_{2} \mathrm{O}: \mathrm{NH}_{3}: \mathrm{CH}_{3} \mathrm{OH}: \mathrm{CO}: \mathrm{CO}_{2}\end{array}$ & $\begin{array}{l}\text { Dose } \\
\frac{\text { photon }}{\text { molec }}\end{array}$ & $\begin{array}{c}\frac{N_{\mathrm{C}}(\mathrm{HMT})^{1}}{N_{\mathrm{C}}(\mathrm{ice})} \\
(\%)\end{array}$ & $\begin{array}{c}\frac{N_{\mathrm{C}}(\text { c.a. salt })^{2}}{N_{\mathrm{C}}(\text { ice })} \\
(\%)\end{array}$ & $\begin{array}{c}\frac{N_{\mathrm{C}}(\text { amide })^{2}}{N_{\mathrm{C}} \text { (ice) }} \\
(\%)\end{array}$ & $\begin{array}{l}\frac{N_{\mathrm{C}}(\text { ester })^{2}}{N_{\mathrm{C}}(\text { ice })} \\
(\%)\end{array}$ & $\begin{array}{c}\frac{N_{\mathrm{C}}(\mathrm{total})^{2}}{N_{\mathrm{C}} \text { (ice) }} \\
(\%)\end{array}$ \\
\hline 1 & standard exp. & $2: 1: 1: 1: 1$ & 0.25 & $6.4 \pm 0.3$ & 1.8 & 0.33 & 0.16 & 8.7 \\
\hline 2 & standard exp. & $2: 1: 1: 1: 1$ & 0.23 & $4.2 \pm 0.1$ & 1.1 & 0.32 & 0.07 & 5.7 \\
\hline 3 & standard exp. & $2: 1: 1: 1: 1$ & 0.26 & $4.4 \pm 0.4^{3}$ & $0.6^{3}$ & $0.09^{3}$ & $0.12^{3}$ & $5.2^{3}$ \\
\hline 4 & & $2: 1: 1: 1: 1$ & 3.33 & $5.6 \pm 0.1$ & 1.5 & 1.2 & 0.9 & 9.2 \\
\hline 5 & & $2: 1: 1: 1: 1$ & 0.031 & $2.4 \pm 0.1$ & 0.3 & 0.04 & 0.10 & 2.8 \\
\hline 6 & dep. at $80 \mathrm{~K}$ & $2: 1: 1: 1: 1$ & 0.33 & $7.0 \pm 0.2$ & 0.9 & 0.53 & 0.15 & 8.6 \\
\hline 7 & soft UV spectrum & $2: 1: 1: 1: 1$ & 0.66 & $7.0 \pm 0.3$ & 0.4 & 0.15 & 0.13 & 7.7 \\
\hline 8 & no irradiation & $2: 1: 1: 1: 1$ & 0 & $\leq 0.1$ & $\leq 0.01$ & $\leq 0.05$ & $\leq 0.05$ & $\leq 0.21$ \\
\hline 9 & & $0: 1: 1: 0: 0$ & 0.32 & $0.6 \pm 0.1$ & 0.09 & 0.27 & 0.05 & $1.0^{4}(1.5)$ \\
\hline 10 & & $2: 1: 0: 0: 0$ & 0.38 & $\leq 0.1^{5}$ & $\leq 0.01^{5}$ & $\leq 0.01^{5}$ & $\leq 0.01^{5}$ & $\leq 0.13^{5}$ \\
\hline 11 & & $2: 1: 0: 1: 0$ & 0.24 & $0.6 \pm 0.1$ & 1.6 & 2.5 & 0.24 & 4.9 \\
\hline 12 & & $2: 1: 0: 1: 1$ & 0.26 & $\leq 0.1$ & 0.3 & 0.78 & 0.02 & 1.2 \\
\hline 13 & & $2: 1: 1: 0: 0$ & 0.25 & $0.4 \pm 0.2$ & 0.08 & $\leq 0.01$ & $\leq 0.01$ & $0.5^{4}(0.8)$ \\
\hline 14 & & $20: 1: 0: 1: 0$ & 0.15 & $1.3 \pm 0.1$ & 0.3 & 1.1 & $\leq 0.01$ & 2.7 \\
\hline 15 & & $20: 1: 1: 0: 0$ & 0.20 & $17.1 \pm 1.7$ & 5.1 & 5.2 & 1.0 & 28.4 \\
\hline 16 & & $20: 1: 1: 1: 1$ & 0.22 & $15.0 \pm 0.7$ & 0.3 & 0.28 & 0.11 & 15.7 \\
\hline
\end{tabular}

${ }^{1}$ Values are the average of the column density values obtained from the 1007 and $1236 \mathrm{~cm}^{-1}$ features of HMT with band strengths shown in Table 3. Errorbars give the difference between both values.

${ }^{2}$ Estimated errors obtained by integration using different baselines are $\leq 20 \%$ of these values. Feature positions are 1586 for c.a. salts, 1680 for amides and $1742 \mathrm{~cm}^{-1}$ for esters. Band strengths used for integration are given in Table 3.

${ }^{3}$ For this experiment the last step of the warm-up was slightly different. At $298 \mathrm{~K}$ the cryostat was switched off as usual, but the heater was kept on, set at $298 \mathrm{~K}$, to guarantee the residue was monitored at constant temperature.

${ }^{4}$ In addition to the listed species, the spectrum shows a large abundance of POM-like species. The values in brackets include the POM abundances assuming the band strength of pure POM (Table 3).

${ }^{5}$ In this experiment no C-containing ice was deposited, values give an upper limit of the carbon column density of the products relative to the total column density of the original ice deposition.

assigned to the $\mathrm{COO}^{-}$antisymmetric stretch of ammonium glycolate $\left[\left(\mathrm{HOCH}_{2} \mathrm{COO}^{-}\right)\left(\mathrm{NH}_{4}^{+}\right)\right]$, which corresponds well with the peak in the OR1 spectrum (Fig. 3).

The fingerprints of HMT are also clearly present in the residue spectrum, mainly through two sharp peaks at 1234 and $1007 \mathrm{~cm}^{-1}$, corresponding to the $v_{21}$ and $v_{22} \mathrm{CN}$ stretch, respectively (Bernstein et al. 1995). A good overall fit of the standard (OR1) residue spectrum is obtained by adding up the ammonium glycolate and HMT spectra at $240 \mathrm{~K}$ (Fig. 3, lower dashed trace). While these products sublimate in the $240-270 \mathrm{~K}$ range if deposited as pure standards under vacuum conditions, matrix effects in the residue, probably due to H-bonded species, prevent them from doing so, since they can be observed at room temperature in the infrared spectrum. The match shows that the overall composition of the residue observed in the mid-infrared is dominated by HMT and carboxylic acid salts. It was earlier found that if $\mathrm{CH}_{3} \mathrm{OH}$ is present in the starting ice mixture, HMT is the most abundant component in the residue (Bernstein et al. 1995). Gas chromatography-mass spectrometry (GC-MS), after derivatization, of residues obtained from the photolysis of $\mathrm{H}_{2} \mathrm{O}: \mathrm{CO}: \mathrm{NH}_{3}=5: 5: 1$ ice (Agarwal et al. 1985; Briggs et al. 1992) showed that carboxylic acids, especially glycolic acid, are abundant components. Carboxylic acids themselves have a low abundance in our experiments, since the strong peak due to the $\mathrm{C}=\mathrm{O}$ stretching mode at $1690-1710 \mathrm{~cm}^{-1}$ is absent (Fig. 3).
Dissociation of the carboxylic acid salts into the acid and base components explains why the products analysed by GC-MS are carboxylic acids, while the in situ infrared results presented here indicate the presence of carboxylic acid salts.

It can be seen from Fig. 3 (bottom) that most of the features in the residue spectrum are reproduced using solely ammonium glycolate and HMT. Nevertheless, the peak intensities are not expected to be fit in this simple fashion, as other carboxylic acids are also present in residues (Agarwal et al. 1985; Briggs et al. 1992). The peak at $1085 \mathrm{~cm}^{-1}$ is characteristic of glycolic acid and it is also present in ammonium glycolate. By matching the intensity of this feature in the standard (OR1) residue spectrum, it can be seen that ammonium glycolate accounts for about $20 \%$ of the $\mathrm{COO}^{-}$stretching mode at $1586 \mathrm{~cm}^{-1}$. The remainder arises from a variety of other carboxylic acid salts, e.g. ammonium glycerate $\left[\left(\mathrm{HOCH}_{2} \mathrm{CH}(\mathrm{OH}) \mathrm{COO}^{-}\right)\left(\mathrm{NH}_{4}^{+}\right)\right]$and ammonium oxamate $\left[\left(\mathrm{NH}_{2} \mathrm{COCOO}^{-}\right)\left(\mathrm{NH}_{4}^{+}\right)\right]$, for which the corresponding acids were found by chemical analysis (Agarwal et al. 1985; Briggs et al. 1992). The minor absorption features at 1742 and $1680 \mathrm{~cm}^{-1}$ are ascribed to the $\mathrm{C}=\mathrm{O}$ stretching mode of esters $\left[\mathrm{R}-\mathrm{C}(=\mathrm{O})-\mathrm{O}-\mathrm{R}^{\prime}\right]$ and primary amides $\left[\mathrm{R}-\mathrm{C}(=\mathrm{O})-\mathrm{NH}_{2}\right]$, respectively (Table 2). A weak band between $1620-1650 \mathrm{~cm}^{-1}$ $\left(\mathrm{NH}_{2}\right.$ deformation of primary amides) becomes visible after the large $1586 \mathrm{~cm}^{-1}$ feature has decreased in intensity (Sect. 4.5, Fig. 11), confirming the presence of primary amides. 


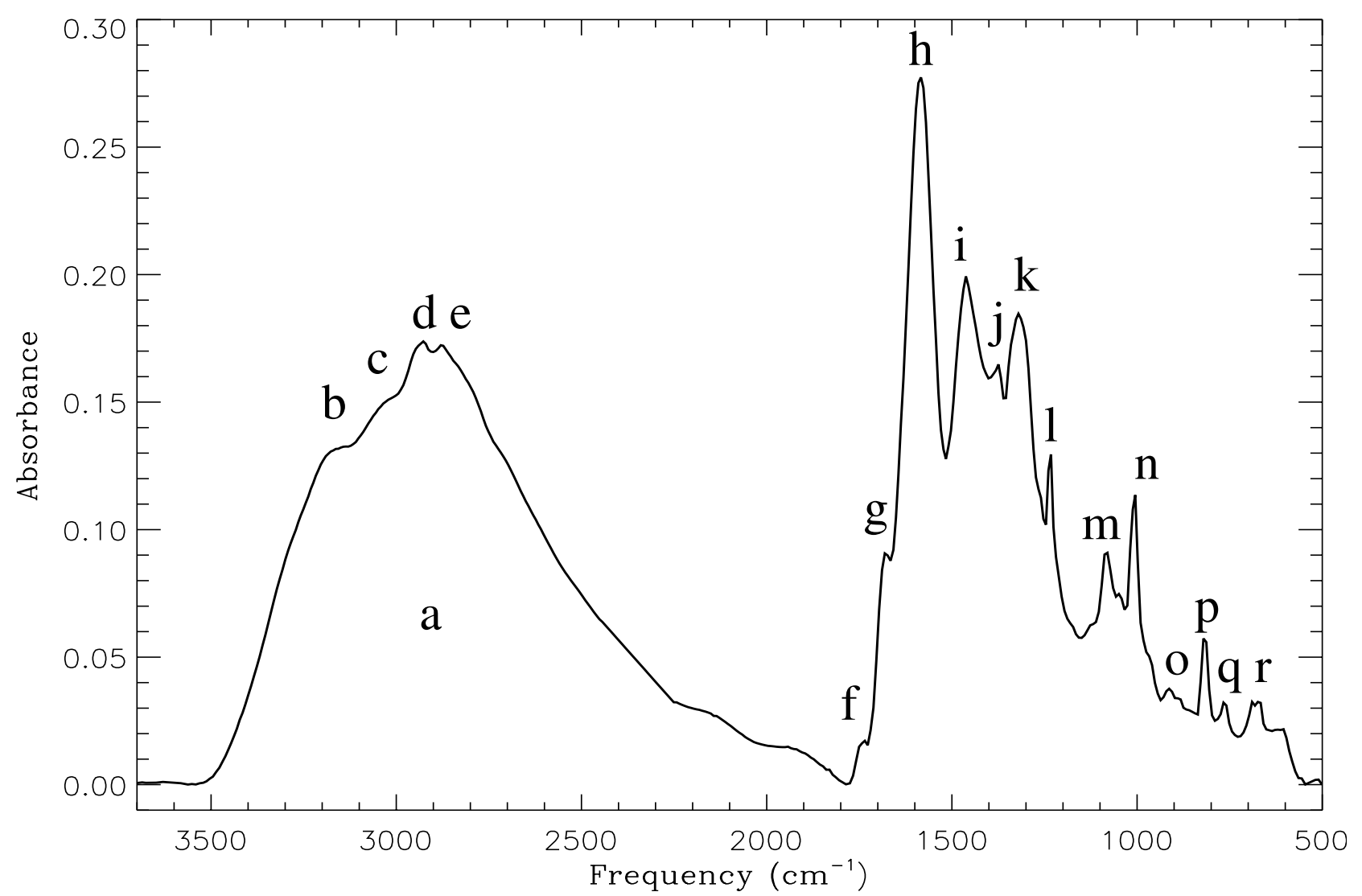

Fig. 2. IR spectrum of the residue of the standard experiment, Exp. OR1. Feature identifications are given in Table 2.

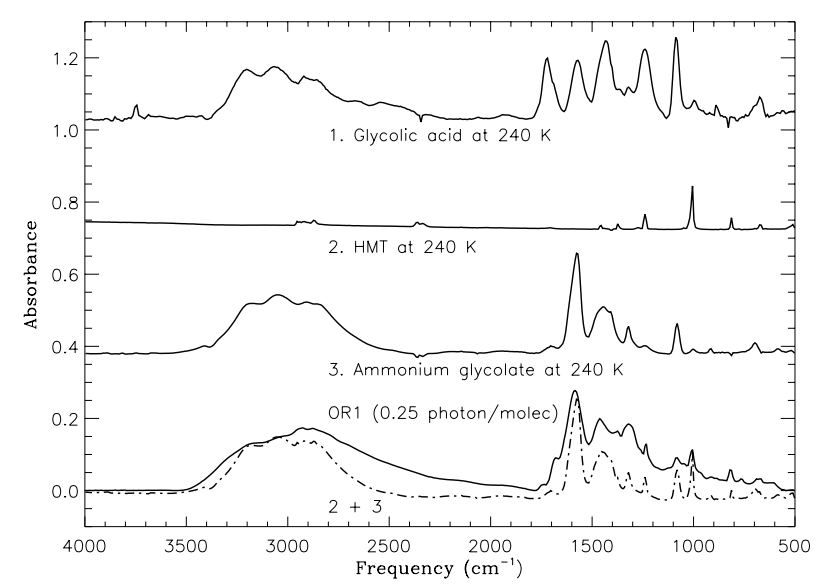

Fig. 3. IR spectrum of the residue of the standard experiment (OR1; solid line, bottom) compared to the reference spectra of possible products. The fit (dashed line) is obtained by addition of spectra 2 and 3 at $240 \mathrm{~K}$, corresponding to ammonium glycolate and HMT.

This finding is consistent with the detection of amides as refractory products of ice photolysis by GC-MS (Agarwal et al. 1985; Briggs et al. 1992; Bernstein et al. 1995).

\subsection{Effect of variation of the experimental parameters}

Table 1 summarizes the abundances of HMT, carboxylic acid (c.a.) salts, amides, esters and the estimated total as found in the residues for the various experiments. The corresponding residue spectra are shown in Figs. 5-10. The carbon column density of component $i, N_{\mathrm{C}}(i)$, in $\mathrm{cm}^{-2}$, was obtained by integration of the corresponding spectral feature:

$N_{\mathrm{C}}(i)=n_{\mathrm{C}}(i) \frac{\int \tau_{\nu} \mathrm{d} v}{A}$

where $n_{\mathrm{C}}(i)$ is the number of carbon atoms in molecule $i, \tau_{v}$ the optical depth of the band, and $A$ the band strength (Table 3 ). $N_{\mathrm{C}}$ (HMT) was calculated from the average of the integration of the 1007 and $1236 \mathrm{~cm}^{-1}$ bands, while $N_{\mathrm{C}}$ (c.a. salt), $N_{\mathrm{C}}$ (amide) and $N_{\mathrm{C}}$ (ester) were obtained from the integration of the 1586 , 1680 and $1742 \mathrm{~cm}^{-1}$ bands, respectively. For the integration of the bands the baseline used was the local continuum.

The production of HMT, carboxylic acid salts, amides, esters and the total is given by the column densities of the carbon in those species, $N_{\mathrm{C}}$ (HMT), $N_{\mathrm{C}}$ (c.a. salts), $N_{\mathrm{C}}$ (amide), $N_{\mathrm{C}}$ (ester) and $N_{\mathrm{C}}$ (total) relative to the total column density of carbon in the original ice deposition, $N_{\mathrm{C}}($ ice $)$. While HMT contains $6 \mathrm{C}$ atoms, $n_{\mathrm{C}}(\mathrm{HMT})=6$, the average number of $\mathrm{C}$ atoms assigned to carboxylic acid salts and amides was $n_{\mathrm{C}}$ (c.a. salt) $=$ 2.2 and $n_{\mathrm{C}}($ amide $)=2.4$, as derived from earlier results (Briggs et al. 1992). For esters, the same value as for amides was assumed, $n_{\mathrm{C}}($ ester $)=2.4$. The results of changing the various experimental parameters are discussed below.

The standard experiment (OR1) was repeated after 6 months to check the reproduceability of the results (OR2, Table 1). The same products were formed, although the abundances obtained for OR2 were $40 \%$ lower than for OR 1 . This could be due to some instability of the UV lamp. The other 
Table 2. Assigned feature carriers of the IR residue spectrum of the standard, Exp. OR1.

\begin{tabular}{|c|c|c|c|}
\hline Feature label & $\begin{array}{c}\text { Position } \\
\mathrm{cm}^{-1}\end{array}$ & Carrier & Vibration mode \\
\hline $\mathrm{a}$ & $3500-2300$ & $\overline{\mathrm{R}-\mathrm{COOH} \text {, alcohols, } \mathrm{NH}_{4}^{+}}$ & OH str., NH str. \\
\hline $\mathrm{b}$ & 3165 & $\mathrm{NH}_{4}^{+a}$ & $v_{1}+v_{5}^{a}$ \\
\hline $\mathrm{c}$ & 3035 & $\mathrm{NH}_{4}^{+a}$ & $v_{2}+v_{4}$ \\
\hline $\mathrm{d}$ & 2926 & $\mathrm{HMT}^{b}$ & $2 v_{19}, v_{2}+v_{19}$ \\
\hline $\mathrm{e}$ & 2876 & $\mathrm{HMT}^{b}, \mathrm{NH}_{4}^{+a}$ & $v_{18}$ sym. $\mathrm{CH}_{2}$ str., $2 v_{4}$ of $\mathrm{NH}_{4}^{+a}$ \\
\hline $\mathrm{f}$ & 1742 & Esters & $\mathrm{C}=\mathrm{O}$ str. \\
\hline $\mathrm{g}$ & 1680 & Amides & $\mathrm{C}=\mathrm{O}$ str. \\
\hline $\mathrm{h}$ & 1586 & $\mathrm{COO}^{-}$in carboxylic acid salts & $\mathrm{COO}^{-}$antisym. str. \\
\hline $\mathrm{i}$ & 1463 & $\mathrm{NH}_{4}^{+a}$ & $v_{4}^{a}$ \\
\hline $\mathrm{j}$ & 1375 & $\mathrm{HMT}^{b}$ & $\mathrm{CH}$ scissoring ${ }^{a}$ \\
\hline $\mathrm{k}$ & 1320 & $\mathrm{COO}^{-}$in carboxylic acid salts & $\mathrm{COO}^{-}$sym. str. \\
\hline 1 & 1236 & $\mathrm{HMT}^{b}$ & $v_{21} \mathrm{CN}$ str. \\
\hline $\mathrm{m}$ & 1085 & $\mathrm{HOCH}_{2} \mathrm{COO}^{-}$ & \\
\hline $\mathrm{n}$ & 1007 & $\mathrm{HMT}^{b}$ & $v_{22} \mathrm{CN}$ str. \\
\hline o & 918 & carboxylic acid dimers & $\mathrm{OH}$ def. \\
\hline $\mathrm{p}$ & 820 & $\mathrm{HMT}^{b}$ & $\mathrm{NH}_{2}$ wag \\
\hline $\mathrm{q}$ & 765 & Ammonium formate? & \\
\hline $\mathrm{r}$ & 678 & $\mathrm{HMT}^{b}$, ammonium glycolate & $v_{24}$ CNC def. (for HMT) \\
\hline
\end{tabular}

${ }^{a}$ Wagner \& Hornig (1950); ${ }^{b}$ Bernstein et al. (1995).

Table 3. Band strengths of molecules used for integration.

\begin{tabular}{ccccc}
\hline \hline Species & Feature & $\begin{array}{c}\text { Position } \\
\mathrm{cm}^{-1}\end{array}$ & $\begin{array}{c}A \\
\mathrm{~cm} \mathrm{molec}^{-1}\end{array}$ & Ref. \\
\hline $\mathrm{H}_{2} \mathrm{O}$ & OH stretch & 3280 & $2.0 \times 10^{-16}$ & $a$ \\
$\mathrm{NH}_{3}$ & umbrella $\left(v_{2}\right)$ & 1070 & $1.7 \times 10^{-17}$ & $b$ \\
$\mathrm{CH}_{3} \mathrm{OH}$ & $\mathrm{CO}$ stretch $\left(v_{8}\right)$ & 1026 & $1.8 \times 10^{-17}$ & $c$ \\
$\mathrm{CO}$ & $\mathrm{CO}$ stretch & 2139 & $1.1 \times 10^{-17}$ & $d$ \\
$\mathrm{CO}_{2}$ & $\mathrm{CO}_{2}$ stretch $\left(v_{3}\right)$ & 2343 & $7.6 \times 10^{-17}$ & $e$ \\
$\mathrm{HMT}$ & ${\mathrm{CN} \mathrm{stretch}\left(v_{21}\right)} 1234$ & $2.6 \times 10^{-18}$ & $f$ \\
$\mathrm{HMT}$ & $\mathrm{CN}$ stretch $\left(v_{22}\right)$ & 1007 & $5.0 \times 10^{-18}$ & $f$ \\
carboxylic acid salts & $\mathrm{COO}$ str. & 1586 & $6.0 \times 10^{-17}$ & $g$ \\
$\mathrm{NH}_{4}^{+}$ & $v_{4}$ & 1463 & $4.0 \times 10^{-17}$ & $h$ \\
amides & $\mathrm{C}=\mathrm{O}$ str. & 1680 & $3.3 \times 10^{-17}$ & $g$ \\
esters & $\mathrm{C}=\mathrm{O}$ str. & 1742 & $2.0 \times 10^{-17}$ & $g$ \\
POM & & 1098 & $9.7 \times 10^{-18}$ & ${ }^{i}$ \\
\hline${ }^{a}$ Hagen et al. $(1981) ;{ }^{b}$ Sandford \& Allamandola $(1993) ;{ }^{c}$ Hudgins et al. $(1993) ;$ \\
${ }^{d}$ Jiang et al. $(1975) ;{ }^{e}$ Yamada \& Person $(1964) ;{ }^{f}$ Bernstein et al. $(1995) ;$ \\
${ }^{g}$ Wexler $(1967) ;{ }^{h}$ Schutte \& Khanna $(2003) ;{ }^{i}$ Schutte et al. $(1993)$, in cm $(\mathrm{C} \text { atom })^{-1}$.
\end{tabular}

experiments were performed within the 3 months after OR1, so that the experimental errors should be lower than $40 \%$.

\subsubsection{UV dose}

The standard ice mixture was irradiated with different UV doses (Exps. OR1, OR4, OR5 and OR7, Table 1). To allow a quantitative comparison, all spectra were normalized to the total amount of carbon deposited in the ice, $N_{\mathrm{C}}$ (ice). The spectra of the different irradiated ice mixtures at $12 \mathrm{~K}$ (showing only the region where new species form) are shown in Fig. 4. The same features show up, although their relative intensities differ for different doses. Likewise, the corresponding residues show similar spectroscopic structure (Fig. 5), but with strong variation in the relative intensities. First, the amount of residue produced increases with the dose up to a maximum. By comparing OR1 and OR5, a factor of 8 increase in the UV dose (from 0.03 to 0.25 photon molec $^{-1}$ ) leads, after normalization by the number of deposited carbon atoms, to three times more residue (Table 1). However, when the dose is increased by another factor 13 (3.3 photon molec $\left.^{-1}\right)$, OR4, the amount of residue remains comparable to OR1 (Table 1), indicating that a general equilibrium is reached at some point between UV induced formation and destruction of complex organics. Furthermore, although the spectral features are similar, the relative intensities are strongly dose dependent. High doses favor ester and amide production with respect to carboxylic acid salts and HMT, as can be seen from the variation of the $1742 \mathrm{~cm}^{-1}$ and $1680 \mathrm{~cm}^{-1}$ features with respect to the $1586 \mathrm{~cm}^{-1}$ and $1007 \mathrm{~cm}^{-1}$ features (Table 1). For the 


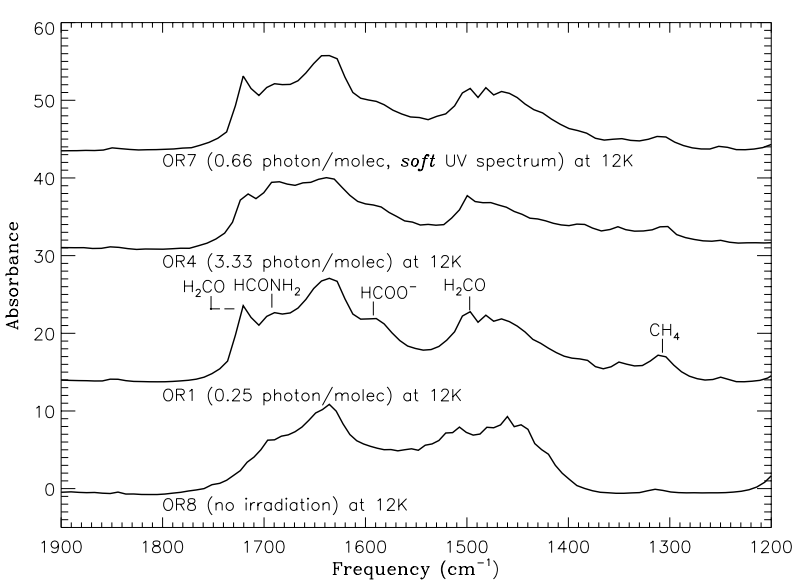

Fig. 4. Comparison of IR spectra of irradiated standard ice mixture at $12 \mathrm{~K}$ for the standard experiment (OR1, dose of 0.25 photon molec $^{-1}$, hard UV spectrum), an experiment with a higher UV dose (OR4, dose of 3.33 photon molec $^{-1}$, hard UV spectrum), and the only experiment performed with the soft UV spectrum (OR7, dose of 0.66 photon molec $\left.^{-1}\right)$. For peak assignments see Schutte et al. (1999), Grim et al. (1989).

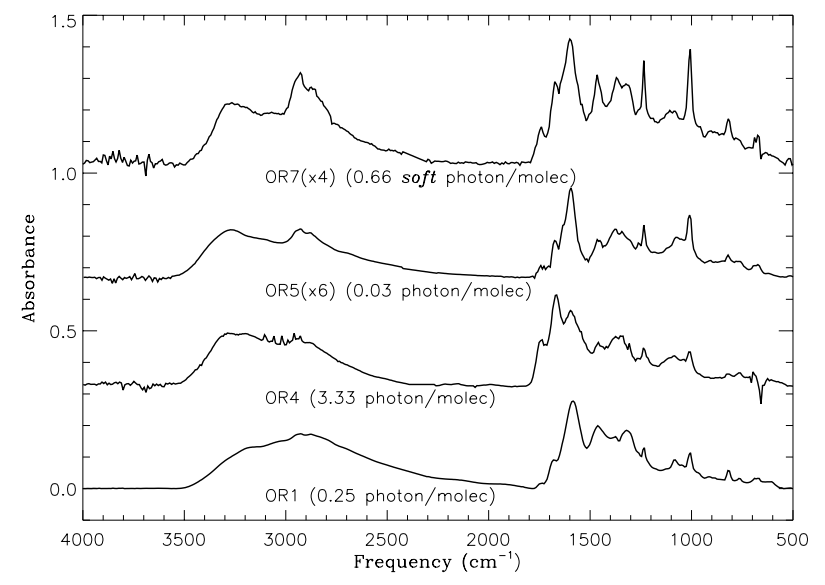

Fig. 5. IR spectra of residues for the same starting ice composition and different irradiation dose, or different UV spectrum.

standard experiment (OR1, with a dose of 0.25 photon molec $^{-1}$ ), the calculated quantum yield of HMT formation, defined as the ratio of the total number of HMT molecules produced to the total number of UV photons impinging on the ice, is $\Phi_{\mathrm{HMT}} \approx 0.01$ molec photon $^{-1}$.

\subsubsection{Photon energy}

For soft UV photons, Exp. OR7 (quartz window, Fig. 1), the production of HMT, relative to other features, is enhanced as compared to hard UV photons, Exps. OR1, OR4, and OR5 $\left(\mathrm{MgF}_{2}\right.$ window, Fig. 1). HMT is as efficiently produced by soft UV photons as it is by hard UV photons. On the other hand, the abundance of carboxylic acids is significantly lower for soft UV photons (Fig. 5, Table 1).

\subsubsection{Ice composition}

Figure 6 shows the IR spectra of the irradiated ice mixture at $12 \mathrm{~K}$ corresponding to the standard (OR1) and the

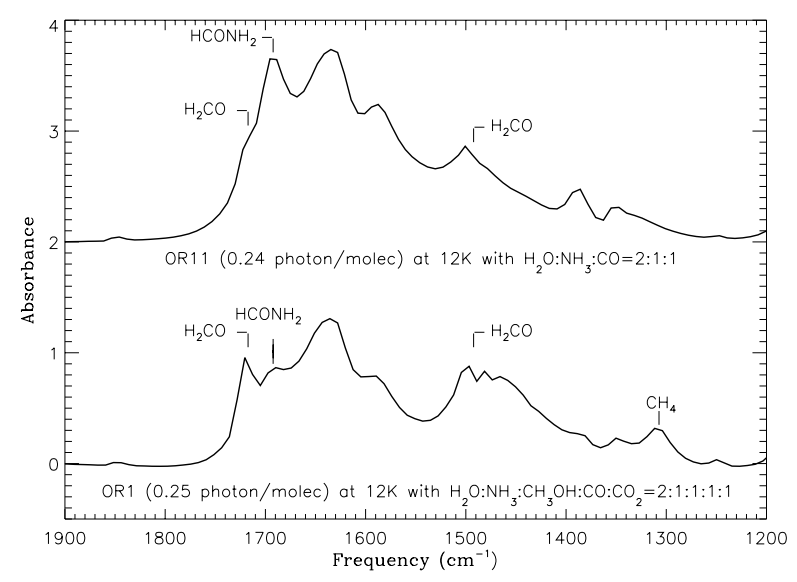

Fig. 6. IR spectra of $12 \mathrm{~K}$ irradiated ice of standard (OR1) and $\mathrm{H}_{2} \mathrm{O}: \mathrm{NH}_{3}: \mathrm{CO}=2: 1: 1$ experiment.

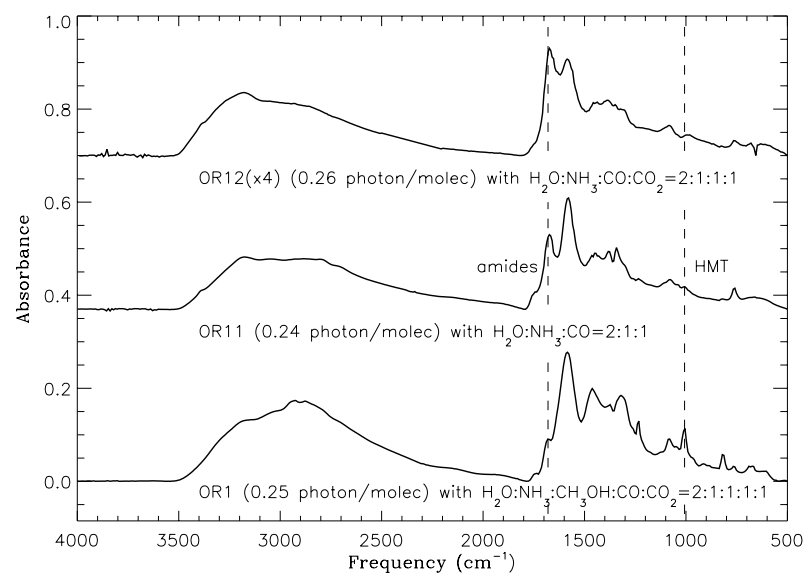

Fig. 7. IR spectra of residues for different starting ice composition to study the effect of excluding $\mathrm{CH}_{3} \mathrm{OH}$ and $\mathrm{CO}_{2}$. Dashed lines indicate the position of the amides and HMT features.

experiment using $\mathrm{H}_{2} \mathrm{O}: \mathrm{NH}_{3}: \mathrm{CO}=2: 1: 1$ ice (OR11). The effects of excluding $\mathrm{CH}_{3} \mathrm{OH}$ and $\mathrm{CO}_{2}$ ice from the standard ice mixture are shown in Fig. 7. When $\mathrm{CH}_{3} \mathrm{OH}$ is excluded, the sharp HMT peaks at $1007 \mathrm{~cm}^{-1}$ and $1234 \mathrm{~cm}^{-1}$ are strongly reduced. Clearly, as previously reported by Bernstein et al. (1995), $\mathrm{CH}_{3} \mathrm{OH}$ is the main contributor to the formation of HMT, although the infrared spectrum shows that HMT can be formed in small amounts in the absence of $\mathrm{CH}_{3} \mathrm{OH}$, as previously found by means of GC-MS (Briggs et al. 1992). This is most likely associated with the efficient formation of $\mathrm{H}_{2} \mathrm{CO}$ from $\mathrm{CH}_{3} \mathrm{OH}$ photolysis, as compared to $\mathrm{H}_{2} \mathrm{CO}$ produced by irradiation of $\mathrm{H}_{2} \mathrm{O}$ and $\mathrm{CO}$ ice (Fig. 6), since $\mathrm{H}_{2} \mathrm{CO}$ is the precursor of HMT (Fig. 13). The $1680 \mathrm{~cm}^{-1}$ feature of amides is strongly enhanced in the absence of $\mathrm{CH}_{3} \mathrm{OH}$ (Fig. 7). The band near $1685 \mathrm{~cm}^{-1}$, the position of formamide $\left[\mathrm{HC}(=\mathrm{O}) \mathrm{NH}_{2}\right]$, forms efficiently at $12 \mathrm{~K}$ with only $\mathrm{CO}$ as C-containing ice, relative to the standard (OR1), which contains $\mathrm{CH}_{3} \mathrm{OH}$ (Fig. 6).

The effects of varying the relative abundance of $\mathrm{NH}_{3}$ were studied by Bernstein et al. (1995). No significant qualitative changes were found in the appearance of the infrared spectrum of the residues obtained from UV-irradiation of the $\mathrm{H}_{2} \mathrm{O}: \mathrm{CH}_{3} \mathrm{OH}: \mathrm{CO}: \mathrm{NH}_{3}=10: 5: 1: 1$ and $\mathrm{H}_{2} \mathrm{O}: \mathrm{CH}_{3} \mathrm{OH}: \mathrm{CO}: \mathrm{NH}_{3}=10: 5: 1: 4.5$ ice mixtures, although 


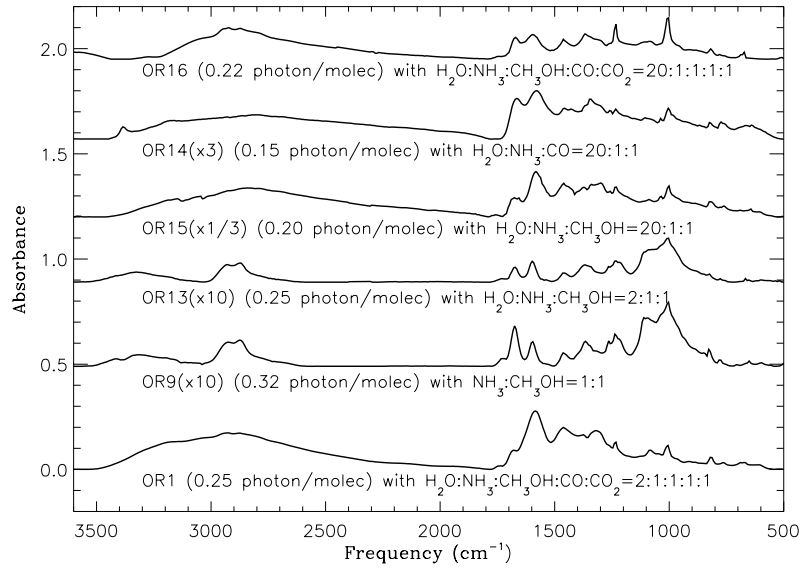

Fig. 8. IR spectra of residues for different ice samples to study the effect of low concentration of organic molecules with respect to water and the result of excluding the $\mathrm{CO}$ and $\mathrm{CO}_{2}$ ices.

some small changes were observed. The total absence of $\mathrm{NH}_{3}$ leads, however, to an infrared spectrum with relatively few features. Therefore, it seems that the residue components depend strongly on the presence of $\mathrm{NH}_{3}$ (Bernstein et al. 1995).

The effect of the $\mathrm{H}_{2} \mathrm{O}$ abundance was investigated in a number of experiments. The residue spectra are shown in Fig. 8. Irradiation of $\mathrm{NH}_{3}: \mathrm{CH}_{3} \mathrm{OH}=1: 1$ ice, OR9, leads to the formation of a broad feature at $1098 \mathrm{~cm}^{-1}$, representative of the $\mathrm{C}-\mathrm{O}$ stretch of aliphatic primary ethers $\left(\mathrm{RCH}_{2}-\mathrm{OCH}_{2} \mathrm{R}\right)$. The exact position of this band corresponds to polyoxymethylene (POM, $\left.\left[\left(-\mathrm{CH}_{2} \mathrm{O}-\right)_{n}\right]\right)$, but the major POM absorption at $932 \mathrm{~cm}^{-1}$ is not present, showing that the carrier is not POM in the pure form. Instead, a strong band feature is found at $1006 \mathrm{~cm}^{-1}$, which is likely caused by a $\mathrm{C}-\mathrm{N}$ or $\mathrm{C}-\mathrm{O}$ stretch mode. The spectral signature of the $1006 \mathrm{~cm}^{-1}$ and $1098 \mathrm{~cm}^{-1}$ features is reminiscent of the POM-like products formed by thermal processing of astrophysical ice analogs containing $\mathrm{H}_{2} \mathrm{CO}$, as well as $\mathrm{NH}_{3}, \mathrm{CH}_{3} \mathrm{OH}$ and $\mathrm{H}_{2} \mathrm{O}$ (Schutte et al. 1993). POM-like species were identified by nuclear magnetic resonance (NMR) spectroscopy in residues (Bernstein et al. 1995). Apparently, due to the high concentration of $\mathrm{H}_{2} \mathrm{CO}$ formed in the $\mathrm{NH}_{3}: \mathrm{CH}_{3} \mathrm{OH}=1: 1$ photolyzed ice, OR9, POM-like structures are formed at the expense of HMT and carboxylic acid salts. The $1680 \mathrm{~cm}^{-1}$ and $1586 \mathrm{~cm}^{-1}$ features of amides and carboxylic acid salts, respectively, are present. Addition of a limited quantity of $\mathrm{H}_{2} \mathrm{O}$ (OR13) gives a similar spectrum with a reduced $1680 \mathrm{~cm}^{-1}$ feature due to amides. When the concentration of $\mathrm{CH}_{3} \mathrm{OH}$ and $\mathrm{NH}_{3}$ is low relative to $\mathrm{H}_{2} \mathrm{O}$ (OR15) the spectrum is similar to the standard experiment (OR1), with no evidence for POM-like species. The produced total carbon measured in the residues is increased by a factor of 20 or more in OR15 (Table 1 and Fig. 8) compared to OR9 and OR13. Surprisingly, the dilution of the $\mathrm{C}$-containing ice components in a large overabundance of $\mathrm{H}_{2} \mathrm{O}$ ice leads to a considerable increase of the conversion to refractory organic species.

Increasing the $\mathrm{H}_{2} \mathrm{O}$ abundance of the standard experiment (OR1) by a factor of 10 (OR16) leads to a high production of HMT and amides and significantly less carboxylic acid salts.

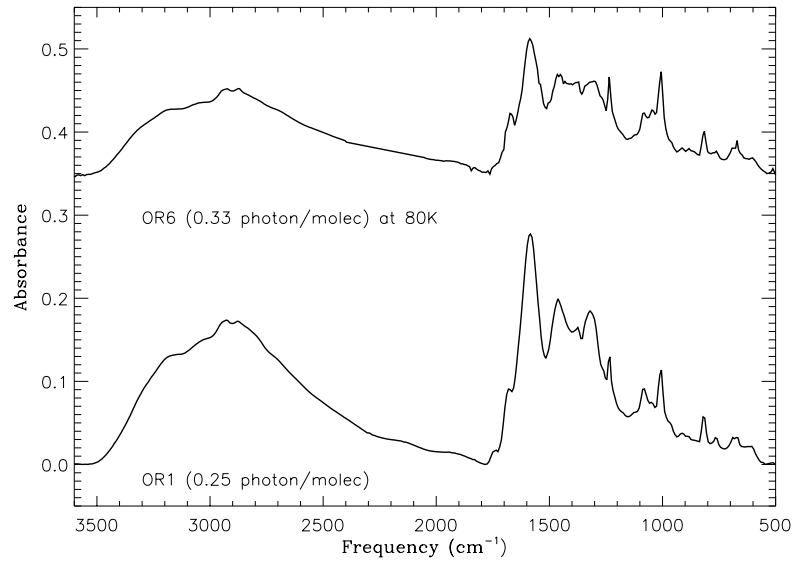

Fig. 9. IR spectra of the residue of the standard experiment (OR1), with deposition and irradiation at $12 \mathrm{~K}$, compared to the residue of the same ice mixture with deposition and irradiation at $80 \mathrm{~K}$ (OR6).

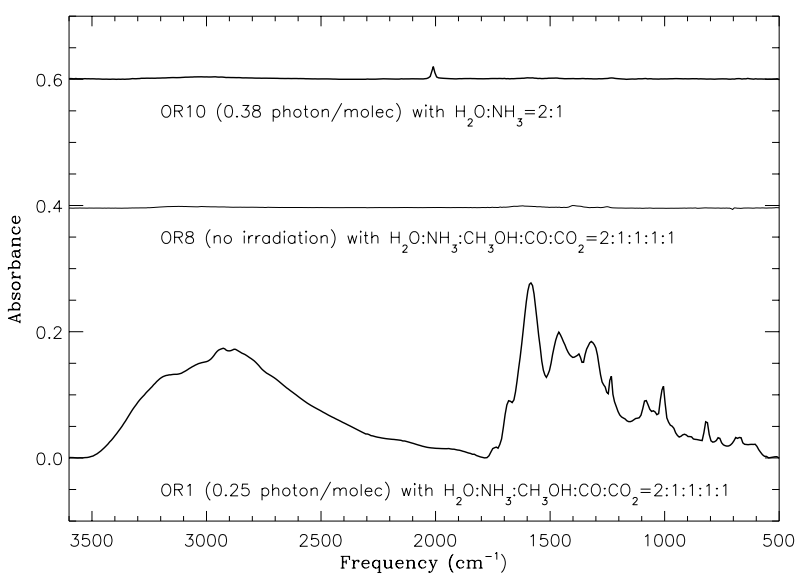

Fig. 10. Blank experiments to find the effect of irradiation and to constrain the influence of possible organic contaminants in the setup.

Again, the conversion of carbon to residue is considerably enhanced, by almost a factor of 2 , in the $\mathrm{H}_{2} \mathrm{O}$-rich ice sample.

\subsubsection{Different deposition temperature}

The standard experiment (OR1) was repeated with deposition and irradiation at $80 \mathrm{~K}$ (OR6), instead of the standard $12 \mathrm{~K}$. At such temperatures $\mathrm{CO}$ does not accrete onto the substrate. The spectra are shown in Fig. 9. There is little difference between the standard, OR1, and the $80 \mathrm{~K}$ experiment, OR6. The only relevant effect is the lower production of carboxylic acid salts, possibly due to the absence of $\mathrm{CO}$ in the ice.

\subsection{Blank experiments}

The standard experiment (OR1) was performed without irradiation (OR8). Possible contamination by organic molecules was checked by irradiating $\mathrm{H}_{2} \mathrm{O}: \mathrm{NH}_{3}=2: 1$ ice, OR10. The resulting room temperature spectra are shown in Fig. 10. In both cases, no residue is formed, with the exception of an unidentified minor peak at $2012 \mathrm{~cm}^{-1}$ in the irradiated experiment. 


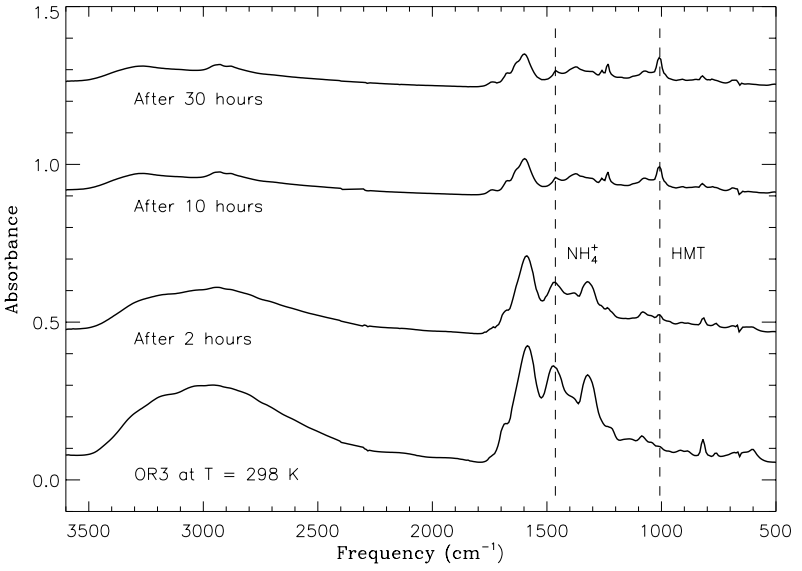

Fig. 11. Time evolution of the residue spectrum (OR3) at room temperature $(T=298 \mathrm{~K})$. The dashed lines indicate the main features of $\mathrm{NH}_{4}^{+}$and HMT.

\subsection{Time and temperature of formation}

To study the temperature of formation of the main residue components, HMT and carboxylic acid salts, the evolution of the infrared spectrum was monitored. The $1575 \mathrm{~cm}^{-1}$ feature of carboxylic acid salts is already present immediately as soon as room temperature is reached. Unfortunately, strong features of volatile ice components mask this band at lower temperatures, preventing the determination of the formation temperature. On the other hand, HMT did not seem to form immediately after room temperature is reached.

In order to monitor the time evolution of the residue at room temperature, an experiment was performed, Exp. OR3, where the last step of the warm-up was slightly different. At $298 \mathrm{~K}$ the cryostat was switched off as usual, but (unlike for the other experiments) the heater was kept on, set at $298 \mathrm{~K}$, to guarantee that the residue was always monitored at this constant temperature. Figure 11 shows the time evolution of the residue, OR3, at room temperature. Immediately after room temperature is reached, no clear sign of HMT is present in the spectrum: it is found that $N(\mathrm{HMT})<4.0 \times 10^{16}$ molec $\mathrm{cm}^{-2}$, less than $1 / 8$ of the amount of HMT observed at the end of the experiment. The HMT features $\left(1236 \mathrm{~cm}^{-1}\right.$ and $1007 \mathrm{~cm}^{-1}$ features) gradually form over the next $10 \mathrm{~h}$. Thus, HMT only forms at the final high temperature stage of the experiment. Meanwhile, the features of the carboxylic acid salts $\left(3500-2300 \mathrm{~cm}^{-1}, 1586 \mathrm{~cm}^{-1}\right.$, and $1463 \mathrm{~cm}^{-1}$ ) decrease. The column density of HMT is plotted against time in Fig. 12, together with the decrease of the ammonium cation, $\mathrm{NH}_{4}^{+}$(this is an essential component for the formation of HMT, see Sect. 5). After $10 \mathrm{~h}$ the formation of HMT stops and no change in the spectrum is observed upon further monitoring for 4 days.

\subsection{Elemental abundances of the residues}

Similar to carbon, see Sect. 4.3, an estimate of the column densities of oxygen and nitrogen can also be obtained. The average number of $\mathrm{O}$ atoms for the residue components are $n_{\mathrm{O}}($ c.a. salt $) \simeq 3.2, n_{\mathrm{O}}($ amide $) \simeq 1.0, n_{\mathrm{O}}($ ester $) \simeq 1.4$ (derived from Briggs et al. 1992; no esters were detected in this work,

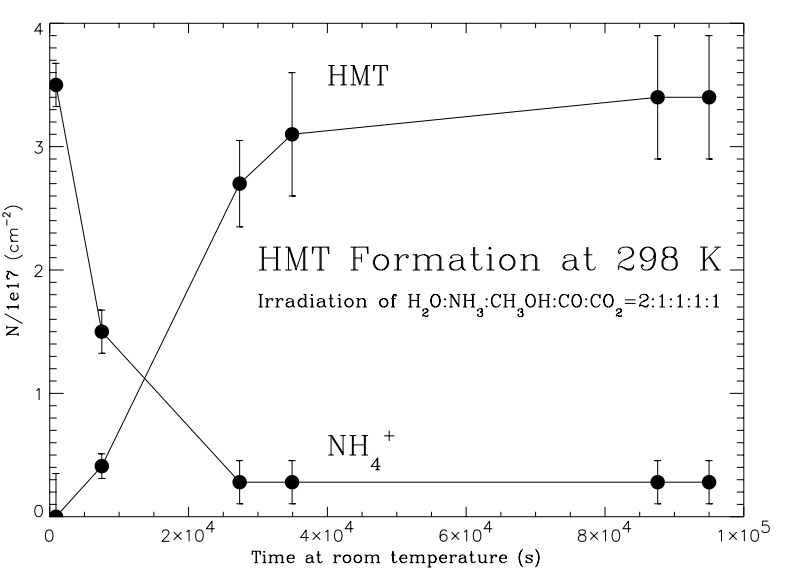

Fig. 12. Time evolution of the column densities of $\mathrm{NH}_{4}^{+}$and HMT (OR3) at room temperature $(T=298 \mathrm{~K})$.

so we assume $n_{\mathrm{O}}($ ester $) \simeq n_{\mathrm{O}}($ amide $)+1$ as there are $2 \mathrm{O}$ atoms in the functional group of esters compared to one for amides) and $n_{\mathrm{O}}(\mathrm{HMT})=0$. For the standard residue, OR1, this gives

$$
\begin{aligned}
\frac{\mathrm{O}}{\mathrm{C}} & =\frac{N_{\mathrm{O}}(\mathrm{HMT})+N_{\mathrm{O}}(\text { c.a. salt })+N_{\mathrm{O}}(\text { amide })+N_{\mathrm{O}}(\text { ester })}{N_{\mathrm{C}}(\mathrm{HMT})+N_{\mathrm{C}}(\text { c.a. salt })+N_{\mathrm{C}}(\text { amide })+N_{\mathrm{C}}(\text { ester })} \\
& \simeq 0.4
\end{aligned}
$$

Using $n_{\mathrm{N}}($ c.a. salt $) \simeq 0.09, n_{\mathrm{N}}($ amide $) \simeq 1.1, n_{\mathrm{N}}($ ester $) \simeq 0.1($ derived from Briggs et al. 1992, for esters we assumed $n_{\mathrm{N}}($ ester $) \simeq$ $n_{\mathrm{O}}$ (amide) -1 as there are no $\mathrm{N}$ atoms in the functional group of esters compared to one $\mathrm{N}$ for amides) and $n_{\mathrm{N}}(\mathrm{HMT})=0.66$. This results in $\frac{\mathrm{N}}{\mathrm{C}} \simeq 0.5$.

\subsection{Comparison to previous results}

For irradiation of ice mixtures containing $\mathrm{H}_{2} \mathrm{O}$, CO, and $\mathrm{NH}_{3}$ with a dose of 0.25 photon molec ${ }^{-1}$, a conversion of $1-2 \%$ of the ice (by mass) into organics was reported (Jenniskens et al. 1993). The values obtained here for a similar dose and comparable ice mixtures are similar (OR11, OR12, and OR14). Bernstein et al. (1995) report an ice-to-residue carbon conversion efficiency of $17.6 \%$ for $\mathrm{H}_{2} \mathrm{O}: \mathrm{CH}_{3} \mathrm{OH}: \mathrm{CO}: \mathrm{NH}_{3}=$ 10:5:1:1 ice. Although no estimation of the UV dose was given in their publication, the fact that they irradiated thin ice layers for $10 \mathrm{~h}$ before the deposition of a new layer, indicates that they used a considerably higher UV dose. This ice mixture was not reproduced in our experiments. The carbon conversion efficiency they report is $\approx 2$ times larger than the standard experiment, OR1, and comparable to OR16. Bernstein et al. (1995) indicate that some HMT or closely related material is produced during photolysis and warm-up to $40 \mathrm{~K}$. Our experiments found no spectroscopic evidence for HMT below room temperature; instead our spectral data clearly show that the formation of HMT takes place at room temperature at the expense of $\mathrm{NH}_{4}^{+}$(see Sect. 4.5). However, our results indicate that the precursors of HMT can form at $12 \mathrm{~K}$ (Sect. 4.5 and sections below), as was previously suggested (Bernstein et al. 1995). 


\section{Discussion of the results}

Our in situ FT-IR spectroscopic results show that carboxylic acid salts are efficiently formed by photo- and thermal processing of interstellar ice analogs. As it will be discussed below, the presence of these salts is crucial for the formation of HMT.

Figure 13 shows the formation pathway of HMT as determined by studies of HMT formation from $\mathrm{H}_{2} \mathrm{CO}$ and $\mathrm{NH}_{3}$ in aqueous solution (Smolin \& Rapoport 1959; Walker 1964). Bernstein et al. (1995) suggested this pathway of HMT formation could also be valid for ice irradiation experiments. It is clear from the IR monitoring of the sample that HMT only forms at room temperature (Sect. 4.5, Figs. 11 and 12). Therefore, the last step in the formation of HMT involving the reaction of 1,3,5-trihydroxymethylhexahydro-1,3,5-triazine with ammonia must occur at room temperature. The former molecule, with mass $177 \mathrm{amu}$, was synthesized at $25^{\circ} \mathrm{C}$ by reaction of amine salts with aqueous $\mathrm{H}_{2} \mathrm{CO}$ under acidic conditions (Narasimhan et al. 1985). Its precursor, hexahydro-1,3,5-triazine, was detected in the residue by GC-MS (Meierhenrich et al. 2003). No 1,3,5-trihydroxymethylhexahydro-1,3,5-triazine was observed, probably because this molecule is readily converted into HMT. While free $\mathrm{NH}_{3}$ has already sublimated at this stage, the ammonia required for step 5 could be supplied by the reverse acid-base reaction between the ammonium cation $\left(\mathrm{NH}_{4}^{+}\right)$ and the carboxylic acid anion $\left(\mathrm{XCOO}^{-}\right)$, Sect. 4.2. This possibility is born out by Fig. 12, showing that the amount of HMT produced is nearly equal to the quantity of $\mathrm{NH}_{4}^{+}$ that is lost at room temperature. An important implication of this is that the presence of ammonium salts is required for the production of HMT in our experiments. At least for some salts of carboxylic acids with ammonia, such as ammonium carbamate $\left[\left(\mathrm{NH}_{2}-\mathrm{COO}^{-}\right)\left(\mathrm{NH}_{4}^{+}\right)\right]$, the dissociation rate is strongly temperature dependent (Ramachandran et al. 1998, and references therein). It is therefore expected that the decomposition rate of the ammonium salts described here would be different for temperatures higher than room temperature, affecting the release of $\mathrm{NH}_{3}$, and consequently the rate of formation of HMT. While the final step in the formation of HMT occurs at high temperature, the preceding four steps should take place at $12 \mathrm{~K}$ during the ice photolysis. This is understood when considering that steps 2 and 4 each require $3 \mathrm{H}_{2} \mathrm{CO}$ molecules, i.e. $N_{\mathrm{H}_{2} \mathrm{CO}}(12 \mathrm{~K}) / N_{\mathrm{C}}(\mathrm{HMT}) \geq 0.5$ is required for both steps. However, for the standard experiment, OR1, comparison of the HMT abundance in the residue with the $\mathrm{H}_{2} \mathrm{CO}$ abundance detected after photolysis at $12 \mathrm{~K}$ gives $N_{\mathrm{H}_{2} \mathrm{CO}}(12 \mathrm{~K}) / N_{\mathrm{C}}(\mathrm{HMT}) \approx 0.25$. For other experiments this ratio can be as low as 0.1 . Clearly, the amount of $\mathrm{H}_{2} \mathrm{CO}$ detected in the photolyzed ice at $12 \mathrm{~K}$ is insufficient to account for the quantity of HMT observed at room temperature. This indicates that all steps involving $\mathrm{H}_{2} \mathrm{CO}$ in the formation pathway of HMT must already take place at $12 \mathrm{~K}$ during photolysis, i.e. up to step 4 . It is likely that copious quantities of $\mathrm{H}_{2} \mathrm{CO}$ are produced at $12 \mathrm{~K}$, either by photodissociation of $\mathrm{CH}_{3} \mathrm{OH}$ (Gerakines et al. 1996) or, to a lesser extent, by addition of $\mathrm{H}$ atoms to $\mathrm{CO}$ (Hudson \& Moore 1999; Hiraoka et al. 2002). Generally, the $\mathrm{H}_{2} \mathrm{CO}$ formed, due to its reactivity,

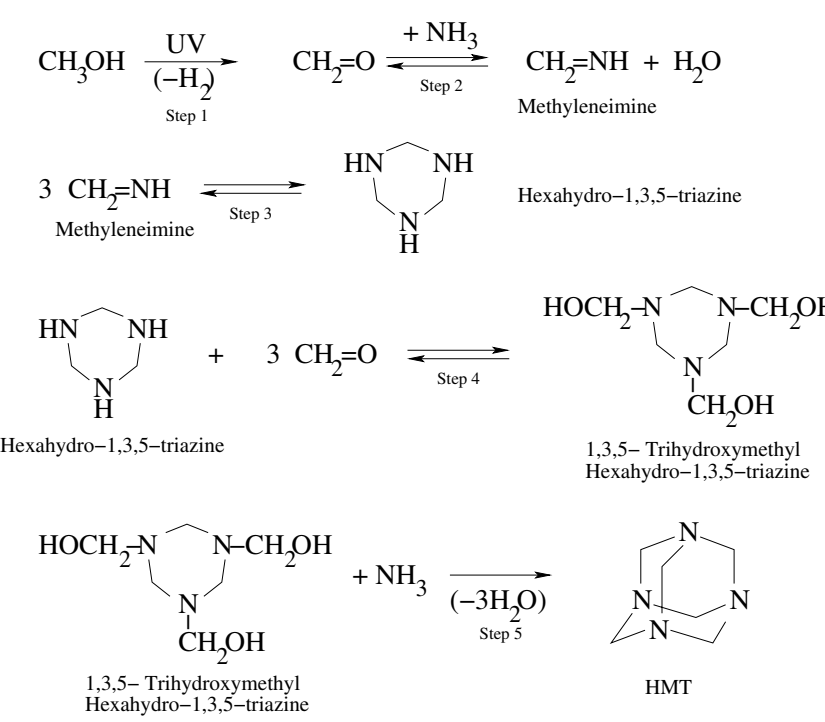

Fig. 13. Chemical pathway for the formation of HMT, after Smolin \& Rapoport (1959), Walker (1964), Bernstein et al. (1995).

will only be a transient, while only a relatively minor fraction becomes stored in the ice. The rest will form more complex species, such as the precursors of the residue components.

The refractory products of ice photoprocessing are very different from the products of thermal processing alone. Generally, UV processing can overcome high activation barriers, leading to thermodynamically favored products, while thermal processing can only overcome low activation barriers leading to unstable species. $\mathrm{H}_{2} \mathrm{CO}$, in the presence of some $\mathrm{NH}_{3}$ can react at $\approx 40 \mathrm{~K}$ to form a variety of thermodynamically unstable species (Schutte et al. 1993). Similar molecules are also formed by photolysis of $\mathrm{NH}_{3}: \mathrm{CH}_{3} \mathrm{OH}\left(: \mathrm{H}_{2} \mathrm{O}\right)=2: 1(: 1)$ ice; these polymers seem to contain $\mathrm{C}-\mathrm{N}$ bonds. However, in all other cases, the main products are HMT and carboxylic acid salts, very different from the molecules obtained by thermal processing alone.

The observed enhancement on the formation of refractory organic molecules diluted in $\mathrm{H}_{2} \mathrm{O}$ ice deserves extra attention. The $\mathrm{H}$ and $\mathrm{OH}$ radicals produced by photodissociation of $\mathrm{H}_{2} \mathrm{O}$ can be incorporated into some of the reaction products (e.g., one of the oxygen atoms in the carboxyl group of glycolic and glyceric acid originates from $\mathrm{H}_{2} \mathrm{O}$; Briggs et al. 1992). Nevertheless, this effect would not be able to account for the enhancement by a factor of $\sim 20$ observed in the formation of organic refractory components in $\mathrm{H}_{2} \mathrm{O}$ dominated ices (OR15 vs. OR9 and OR13, Table 1). In the case of the standard, $\mathrm{OR} 1$, a larger $\mathrm{H}_{2} \mathrm{O}$ ice abundance also increases the production of organics by almost a factor of $\sim 2$ (OR16 vs. OR1, Table 1). Recent quantum chemical calculations show that the addition of $\mathrm{H}_{2} \mathrm{CO}$ to $\mathrm{NH}_{3}$, leading to $\mathrm{HOCH}_{2} \mathrm{NH}_{2}$ or $\left(\mathrm{HOCH}_{2}\right)_{2} \mathrm{NH}$ is significantly enhanced when the process occurs within a $\mathrm{H}_{2} \mathrm{O}$ ice matrix, enabling such reactions at temperatures below $100 \mathrm{~K}$ (Woon 2001). Therefore, our experimental results confirm the theoretical calculations on the important role played by $\mathrm{H}_{2} \mathrm{O}$ ice as a catalyst in the formation of large organic molecules at cryogenic temperatures. 
Table 4. Diagnostics of conditions in molecular clouds or solar nebula from the composition of the residue (cf. Sect. 4; Table 1).

\begin{tabular}{cc}
\hline \hline Molecular probes in the IR & Diagnostic of ... \\
\hline $\mathrm{COO}^{-}$vs. HMT & $\mathrm{CO} / \mathrm{CO}_{2} / \mathrm{CH}_{3} \mathrm{OH}$ ratio, $\mathrm{H}_{2} \mathrm{O}$ ice dilution, $\mathrm{UV}$ dose, hard/soft UV, ice irradiation temp. \\
Amides vs. HMT & $\mathrm{UV}$ dose \\
Amides vs. $\mathrm{COO}^{-}$ & $\mathrm{UV}$ dose \\
Esters vs. HMT & $\mathrm{UV}$ dose \\
Esters vs. $\mathrm{COO}^{-}$ & $\mathrm{UV}$ dose \\
Amides vs. total & $\mathrm{CO} / \mathrm{CH}_{3} \mathrm{OH}$ ratio \\
HMT vs. total & $\mathrm{UV}$ dose, $\mathrm{CO} / \mathrm{CO}_{2} / \mathrm{CH}_{3} \mathrm{OH}$ ratio, $\mathrm{H}_{2} \mathrm{O}$ ice dilution \\
POM-like species & Low $\mathrm{H}_{2} \mathrm{O}$ concentration \\
Organics vs. ice & $\mathrm{UV} \mathrm{dose}, \mathrm{H}_{2} \mathrm{O}$ ice dilution \\
\hline
\end{tabular}

\section{Astrophysical implications}

Complex organic molecules are present in a large variety of environments in space. Carbonaceous chondrites contain carboxylic acids, amino acids, aromatic hydrocarbons and alcohols with concentrations of a few hundred parts per million of the $\mathrm{C}$ abundance. Glycolic acid, the most abundant carboxylic acid produced in our experiments was found in the Murchison meteorite (Cronin et al. 1988). The chemical analysis of IDPs, believed to be of cometary origin, is technically more troublesome than that of meteorites, as the size particles are very small, from 10-200 $\mu \mathrm{m}$ (Stephan et al. 1994). They are known to contain a large fraction of organic molecules, many of them still unidentified. The presence of the IR feature assigned to the carbonyl functional group $(\mathrm{C}=\mathrm{O})$ is evidence for O-containing organics (Flynn et al. 2002). Comets preserve the most pristine material in the solar system. These bodies are formed by agglomeration of dust particles of interstellar and/or solar nebula origin in the outer parts of the solar nebula. Cometary dust is rich in organics, as much as $50 \%$ by mass (Fomenkova 1999). A large fraction of the cometary organics, about $50 \%$, are oxygen-rich $(\mathrm{O} / \mathrm{C} \geq 0.4)$; these compounds are consistent with structures of alcohols, aldehydes, ketones, acids and amino acids, and their salts, although the exact makeup of these molecules can not be unambiguously identified (Fomenkova 1994, 1999). The O/C ratio of the oxygen-rich fraction in comets is similar to the residue of the standard experiment, OR1 (Sect. 4.6). Our experiments suggest that such cometary species may have been produced by photolysis of ices in the ISM or the solar nebula. By comparing the abundance ratios of different classes of molecules in comets to our experimental results, see Table 1, it is possible to evaluate the parameters that played a role on the early evolution of cometary ices, and therefore make a diagnostic of the conditions in the molecular cloud or solar nebula environments. Table 4 shows how the abundance ratios of different classes of molecules can be used as tracers of such conditions. In particular, estimations can be made of the total UV exposure of the ices and the abundance ratios of the ices before irradiation.

The most abundant species, like HMT and carboxylic acids, could be searched for in the radio and $\mathrm{mm}$ spectral region, in environments where ice mantles evaporate, like hot cores, although the large partition function of such large species may result in weak lines difficult to observe. Less abundant residue species, like amino acids
(Bernstein et al. 2002; Muñoz Caro et al. 2002), would be even more difficult to observe. Nevertheless, the excess emission of the $6.0 \mu \mathrm{m}\left(\sim 1670 \mathrm{~cm}^{-1}\right)$ feature towards embedded massive protostars in dense clouds was ascribed to organic residues that were exposed to long-term solar ultraviolet radiation on the EURECA satellite (Gibb \& Whittet 2002; Greenberg et al. 1995). However, this feature is not present in the samples reported here, obtained from ice exposure with a dose of 0.25 photon molec $^{-1}$, which should be more characteristic of the dense medium. Instead, the spectrum of our samples is dominated by the $\mathrm{XCOO}^{-}$feature at $1586 \mathrm{~cm}^{-1}$, which was not detected in the ice spectra towards protostars (Keane et al. 2001). It would be quite unexpected if the organic material produced in dense clouds would be similar to the highly processed residues on board EURECA, which are thought to be representative of organic solids in the diffuse ISM (Greenberg et al. 1995). Instead, organic material in the dense ISM should rather be analogous to the residues reported here. The analysis of cometary organics may help to resolve this issue. The molecules reported in this paper would be very difficult to observe by astronomical IR observations, since the broad features of the volatile ices $\left(\mathrm{H}_{2} \mathrm{O}, \mathrm{CH}_{3} \mathrm{OH}\right.$, etc. $)$ will hide those of minor organic components.

The detection of POM-like species in comets is not direct evidence for thermal processing without irradiation (Schutte et al. 1993), since depending on the ice composition, such species may also be formed by photoprocessing (Sect. 4.3.3). Detailed analysis of the nature of the POM-like material created under various conditions in the laboratory (UV, thermal) is required to interpret the origin of the POM-like species. The detection of POM in the coma of Halley by means of mass spectrometry, with mass differences between peaks of $15 \pm 1 \mathrm{amu}$ (Huebner \& Boice 1987), leaves room for a POM structure including NH groups; it was argued, however, that the observed mass spectrum could be due to a CHON molecule and not necessarily a polymer (Mitchell et al. 1992). The infrared feature of comet Borrelly ascribed to POM is far too noisy to draw any conclusions (Soderblom et al. 2002).

Our experiments show that the organic composition of comets may be used as an indicator of the environmental conditions in which they formed, i.e., the original dense cloud or the solar nebula. Ongoing and future cometary missions (Stardust, Rosetta), together with experimental simulations, are therefore promising, as they may shed new light on the early history of 
our solar system and provide direct information on the ambient conditions in the solar nebula.

Acknowledgements. C. J. Shen kindly provided us with his results before publication. We thank G. Lodder, J. Lugtenburg, G. Marel, H. S. Overkleeft, E. Pantoja and A. van der Gen for discussions on the chemical aspects. We are most thankful to J. M. Greenberg, who died on 29 November 2001, for his encouragement and discussions. G.M.M.C. thanks the Max-Planck-Institut für Aeronomie at Katlenburg-Lindau for a fellowship, during which part of this work was performed. This paper profited from the useful comments made by an anonymous referee.

\section{References}

Agarwal, V. K., Schutte, W. A., Greenberg, J. M., et al. 1985, Origins of Life and Evolution of the Biosphere, 16, 21

Aikawa, Y., Miyama, S. M., Nakano, T., \& Umebayashi, T. 1996, ApJ, 467,684

Aikawa, Y., \& Herbst, E. 1999, A\&A, 351, 233

Aikawa, Y., van Zadelhoff, G. J., van Dishoeck, E. F., \& Herbst, E. 2002, A\&A, 386, 622

Bernstein, M. P., Sandford, S. A., Allamandola, L. J., Chang, S., \& Scharberg, M. A. 1995, ApJ, 454, 327

Bernstein, M. P., Dworkin, J. P., Sandford, S. A., Cooper, G. W., \& Allamandola, L. J. 2002, Nature, 416, 401

Briggs, R., Ertem, G., Ferris, J. P., et al. 1992, Origins of Life and Evolution of the Biosphere, 22, 287

Beuther, H., Kramer, C., Deiss, B., \& Stutzki, J. 2000, A\&A, 362, 1109

Beuther, H., Schilke, P., Menten, K. M., et al. 2002, ApJ, 566, 945

Cottin, H., Szopa, C., \& Moore, M. H. 2001, ApJ, 561, L139

Cronin, J. R., Pizzarello, S., \& Cruikshank, D. P. 1988, in Meteorites and the Early Solar System, ed. J. F. Kerridge, \& M. S. Matthews (Tucson: Univ. of Arizona Press), 819

Dartois, E., Demyk, K., d'Hendecourt, L., \& Ehrenfreund, P. 1999, A\&A, 351, 1066

d'Hendecourt, L. B., Allamandola, L. J., Baas, F., \& Greenberg, J. M. 1982, A\&A, 109, L12

Ehrenfreund, P., Kerkhof, O., Schutte, W. A., et al. 1999, A\&A, 350, 240

Flynn, G. J., Keller, L. P., Joswiak, D., \& Brownlee, D. E. 2002, in 33rd Annual Lunar and Planetary Science Conf., Houston, Texas, abstract 1320

Fomenkova, M. N., Chang, S., \& Mukhin, L. M. 1994, Geoch. Cosmoch. Acta, 58, 4503

Fomenkova, M. N. 1999, Space Sci. Rev., 90, 109

Gerakines, P. A., Schutte, W. A., Greenberg, J. M., \& van Dishoeck, E. F. 1995 , A\&A, 296, 810

Gerakines, P. A., Schutte, W. A., \& Ehrenfreund, P. 1996, A\&A, 312, 289

Gerakines, P. A., Whittet, D. C. B., Ehrenfreund, P., et al. 1999, ApJ, 522,357

Gibb, E. L., Whittet, D. C. B., \& Chiar, J. E. 2001, ApJ, 558, 702

Gibb, E. L., \& Whittet, D. C. B. 2002, ApJ, 566, L113

Greenberg, J. M. 1986, in The Galaxy and the Solar System (Tucson: Univ. of Arizona Press), 103

Greenberg, J. M., Li, A., Mendoza Gómez, C. X., et al. 1995, ApJ, 455, L177

Grim, R. J. A., Greenberg, J. M., de Groot, M. S., et al. 1989, A\&AS, 78,161

Gürtler, J., Klaas, U., Henning, Th., et al. 2002, A\&A, 390, 1075
Hagen, W., Tielens, A. G. G. M., \& Greenberg, J. M. 1981, Chem. Phys., 56, 367

Herbig, G. H., \& Goodrich, R. W. 1986, ApJ, 309, 294

Hiraoka, K., Sato, T., Sato, S., et al. 2002, ApJ, 577, 265

Hudgins, D. M., Sandford, S. A., Allamandola, L. J., \& Tielens, A. G. G. M. 1993, ApJS, 86, 713

Hudson, R. L., \& Moore, M. H. 1999, Icarus, 140, 451

Huebner, W. F., \& Boice, D. C. 1987, ApJ, 320, L149

Jenniskens, P., Baratta, G. A., Kouchi, A., et al. 1993, A\&A, 273, 583

Jiang, G. J., Person, W. B., \& Brown, K. G. 1975, J. Chem. Phys., 64, 1201

Kaiser, R. I., \& Roessler, K. 1998, ApJ, 503, 959

Keane, J. V., Tielens, A. G. G. M., Boogert, A. C. A., Schutte, W. A., \& Whittet, D. C. B. 2001, A\&A, 376, 254

Kim, S-H., Martin, P. G., \& Hendry, P. D. 1994, ApJ, 422, 164

Kissel, J., \& Krueger, F. R. 1987, Nature, 326, 755

Kobayashi, K., Kamamatsu, T., Kaneko, T., et al. 1995, Adv. Sp. Res., 16,21

Meierhenrich, U. J., Muñoz Caro, G. M., Schutte, W. A., et al. 2003, in preparation

Mennella, V., Muñoz Caro, G. M., Ruiterkamp, R., et al. 2001, A\&A, 367,355

Mitchell, D. L., Lin, R. P., Carlson, C. W., et al. 1992, Icarus, 98, 125

Muñoz Caro, G. M., Ruiterkamp, R., Schutte, W. A., Greenberg, J. M., \& Mennella, V. 2001, A\&A, 367, 347

Muñoz Caro, G. M., Meierhenrich, U. J., Schutte, W. A., et al. 2002, Nature, 416, 403

Muñoz Caro, G. M., Meierhenrich, U. J., Schutte, W. A., et al. 2003, submitted to A\&A

Narasimhan, S., Balakrishnam, M., Kumar, A. S., \& Venkatasubramanian, N. 1985, Indian J. of Chem., 24B, 568

Oró, J. 1961, Nature, 190, 389

Prinn, R. G. 1993, in Protostars and Planets III, ed. E. H. Levy, \& J. I. Lunine (Tucson: Univ. of Arizona), 1005

Ramachandran, B. R., Halpern, A. M., \& Glendening, E. D. 1998, J. Phys. Chem. A, 102, 3934

Sandford, S. A., \& Allamandola, L. J. 1993, ApJ, 417, 815

Schutte, W. A., Allamandola, L. J., \& Sandford, S. A. 1993, Icarus, 104,118

Schutte, W. A., Boogert, A. C. A., Tielens, A. G. G. M., et al. 1999 , A\&A, 343, 966

Schutte, W. A., \& Khanna, R. K. 2003, A\&A, 398, 1049

Shen, C. J., Greenberg, J. M., Schutte, W. A., \& van Dishoeck, E. F. 2003, for submission to A\&A

Smolin, E. M., \& Rapoport, L. 1959, The chemistry of heterocyclic compounds. S. Triazines and derivatives (New York: Interscience), 26

Soderblom, L. A., Becker, T. L., Bennett, G., et al. 2002, Science, 296, 1087

Spaans, M., Hogerheijde, M. R., Mundy, L. G., \& van Dishoeck, E. F. 1995, ApJ, 455, L167

Spaans, M., \& van Dishoeck, E. F. 1997, A\&A, 323, 953

Stephan, T., Thomas, K. L., \& Warren, J. L. 1994, Meteoritics, 29, 536

Strazzulla, G., \& Baratta, G. A. 1992, A\&A, 266, 434

Taban, I. M., Schutte, W. A., Pontoppidan, K. M., \& van Dishoeck, E. F. 2003, A\&A, 399, 169

Wagner, E. L., \& Hornig, D. F. 1950, J. Chem. Phys., 18, 296

Walker, J. F. 1964, Formaldehyde (New York: Reinhold Publishing Co.), 511

Weber, P., \& Greenberg, J. M. 1985, Nature, 316, 403

Wexler, A. S. 1967, Appl. Spectrosc. Rev., 1, 29

Whittet, D. C. B., Gerakines, P. A., Tielens, A. G. G. M., et al. 1998, ApJ, 498, 159

Woon, D. E. 2001, J. Phys. Chem. A, 105, 9478

Yamada, H., \& Person, W. B. 1964, J. Chem. Phys., 41, 2478 